NBER WORKING PAPER SERIES

IMPERFECT ANNUITY MARKETS, UNINTENDED BEQUESTS, AND THE OPTIMAL AGE STRUCTURE OF SOCIAL SECURITY BENEFITS

Martin Feldstein

Working Paper No. 2820

NATIONAL BUREAU OF ECONOMIC RESEARCH

1050 Massachusetts Avenue

Cambridge, MA 02138

January 1989

This research is part of NBER's research program in Taxation. Any opinions expressed are those of the author not those of the National Bureau of Economic Research. 
NBER Working Paper \#2820

January 1989

IMPERFECT ANNUITY MARKETS, UNINTENDED BEQUESTS, AND THE OPTIMAL AGE STRUCTURE OF SOCIAL SECURITY BENEFITS

\section{ABSTRACT}

The social security program now provides a constant real benefit throughout each retiree"s 1 ifetime. This paper examines whether total welfare would rise if benefits were lower in early retirement years (when most individuals have some saving with which to finance consumption) arid higher in later years (when the uncertainty of survival and the absence of actuarially fair private annuities makes the availability of social security benefits more important.)

The analysis shows that there is a potentially important difference between the structure of benefits that would be preferred by the current population of workers and retirees and the structure of beriefits that would maximize the steady state level of social welfare. This difference reflects the role of unintended bequests.

The provision of higher benefits to older retirees reduces individualiy optimal savings and therefore the level of unintended bequests. While those bequests may have no value to the retirees, they are clearly of value to the young workers who will receive those tequests. More generally, the system of level benefits raises the steady state level of the capital stock and of total real income.

The present paper provides an explicit analysis of a case in which the current workers want benefits to increase with age while the social security system that maximizes steady state welfare would provide higher benefits to young retirees than to the very old.

Martin Feldstein

National Bureau of Economic Research 1050 Massachusetts Avenue Cambridge, MA 02138 


\title{
Imperfect Annuity Markets, Unintended Bequests, and the \\ Optimal Age Structure of Social Security Benefits
}

\author{
Martin Feldstein ${ }^{*}$
}

Although individuals can save while they are working to finance consumption during their retirement years, they cannot purchase actuarially fair annuities with which to spread their accumulated wealth over an uncertain retirement period. Because insurance companies cannot know as much about individuals' health and life expectancy as the individuals themselves, an adverse selection problem leads to the underprovision of annuity insurance. ${ }^{1}$ As a result, individuals are forced to leave involuntary bequests and to consume less during their retirement and preretirement years than an actuarial fair annuity would permit.

In contrast to the limited voluntary private annuity market, compulsory public social security retirement systems can provide actuarial fair annuities. This feature is a potentially important justification for mandating social security retirement benefits even though the implicit return on social security is less than the return on private investments. ${ }^{2}$

* Professor of Economics, Harvard University, and President of the National Bureau of Economic Research. This paper is part of the NBER study of the government budget and the economy. I am grateful for comments on an earlier draft from Douglas Elmendorf, John Flemming, Efraim Sadka, Lawrence Summers, Alan Viard and participants in the 1987 NBER Summer Institute Workshop on the Economics of the Aged and in the NBER/LSE Transatlantic Public Economics Seminar. 
It is perhaps surprising therefore that in practice the social security program provides each retiree with a real benefit that is fixed for life. It seems at least plausible that the social security program should instead provide a lower level of benefits in the early retirement years (when most individuals have savings with which to finance consumption) and a higher level of benefits in later years (when the uncertainty of survival and the absence of actuarial fair private annuities makes the availability of social security benefits more important). The present paper examines this conjecture and shows the types of conditions under which it may be true.

The paper also indicates that there is a potentially important difference between the structure of benefits that would be preferred by the current population of workers and retirees and the structure of benefits that would maximize the steady state level of social welfare. This difference reflects the role of unintended bequests. The provision of higher benefits in old age (i.e., in the later retirement years) reduces the amount that rational individuals will save for their old age. This reduced saving implies a reduced level of unintended bequests. While those bequests may have little or no value in the eyes of the retirees, they are clearly of value to the younger individuals who receive those bequests. If the level of bequest to be received by those who are currently alive reflects the social security benefit rules that existed in the past, those who are currently alive may favor a system in which benefits rise with age even if everyone would prefer to live in an economy in which security benefits are and previously have been a constant real annuity. The present paper provides an explicit analysis of a case in which the current workers 
want benefits to increase with age while the social security system that maximizes steady state welfare would provide higher benefits to young retirees than to the very old.

It is useful to begin the analysis of the optimal age distribution of social security benefits by considering the simple but extreme case in which individuals are completely myopic: they do no saving and are therefore completely dependent on social security benefits for their retirement consumption. Since such individuals do not save, there are no unintended bequests and therefore no distinction between the optimal structure of benefits from the vantage point of retirees and of younger workers. The socially optimal structure of benefits maximizes the welfare of retirees. Section 1 discusses the optimal age profile of social security benefits in such an economy.

Section 2 then goes to the opposite extreme and considers the structure of benefits that would be preferred by a young worker who is a rational life-cycle saver but who ignores the value of the unintended bequests received by the next generation. The structure of benefits that maximizes the utility of such an individual is shown to depend in a very simple way on the implicit rate of return on social security, the return on private saving, and the probability that young retirees survive to old age. It is shown that this solution also corresponds to the benefit structure that maximizes the welfare of all those alive at a point in time.

The third section derives the socially optimal benefit structure when the effect of the benefit structure on the value of the unintended bequests received by the next generation of workers is explicitly recognized. The analysis shows that recognizing the value of unintended bequests can 
reverse the desired age structure of benefits. The desirability of providing an actuarially fair annuity can be outweighed by the inefficiency of social security as a savings vehicle when the excess savings are transferred to the next generation through unintended bequests.

The analysis in this paper is restricted to extremely simple models in order to separate the effects of imperfect annuity markets, individual myopia, and the value of unintended bequests. A realistic analysis of the optimal age structure of social security benefits would have to recognize that the extent of economic myopia varies in the population ${ }^{3}$ and that some bequests are intended. ${ }^{4}$ A more complete discussion would also consider the character of private group pension annuities, the possibility of means testing additional benefits for the very old $d^{5}$ of a funded social security system instead of the current pay-as-you-go approach, etc..

\section{The optimal Annuity Structure with Complete Myopia}

The economy examined in this paper is an extension of the overlapping generations model first developed by Samuelson (1958). Instead of the Samuelsonian two-period framework, individuals are assumed here to work for two period and then retire for either one or two periods. All individuals are alike and each has a probability $p$ of surviving to the second retirement period. The population grows at rate $n$ per period and wages grow at rate $\mathrm{g}$.

If the number of new retirees at time $t$ is $R_{t}$, the number of older retirees who survived from the previous generation of new retirees is $\mathrm{pR}_{t-1}$ : The social security program pays benefits of $b_{1 t}$ to the younger retirees at time $t$ and $b_{2 t}$ to the older retirees at time $t$. 
All workers at each point in time are paid the same wage, $w_{t}$. If the total number of workers at time $t$ is denoted $L_{t}$ and the social security tax rate is $\theta$, the social security tax collections are $\mathrm{T}_{t}-\theta \mathrm{w}_{t} \mathrm{~L}_{t}$. The payas-you-go nature of the social security program implies the budget constraint:

(1) $b_{1 t} R_{t}+b_{2 t} p R_{t-1}=\theta w_{t} L_{t}$.

To focus on the optimal age structure of the annuity, I will assume that the social security tax rate $(\theta)$ and therefore total social security benefits $\left(T_{t}\right)$ are fixed. Since individuals are myopic and therefore do no saving, the appropriate welfare criterion in this section can be written as a function of the retirees' consumption only.

Each individual's utility during retirement will be written in the separable form $u\left(c_{3}\right)+v\left(c_{4}\right)$ where $c_{3}$ is consumption during the first retirement period (i.e., the third period of life) and $c_{4}$ is the consumption during the second period of retirement if the individual survives to have that consumption. I take the relevant measure of social welfare in each period to be the sum of the utilities of the retirees alive in that period (since the utility of the myopic workers is independent of the structure of the retirement benefits):

(2) $w_{t}-R_{t} \cdot u\left(c_{3 t}\right)+p R_{t-1} \cdot v\left(C_{4 t}\right)$

Since individuals do no saving, all retirement consumption is financed by social security: $c_{3 t}=b_{1 t}$ and $c_{4 t}-b_{2 t}$. The optimal design of the social security benefits is then equivalent to maximizing 
(3) $w_{t}=R_{t} \cdot u\left(b_{1 t}\right)+p R_{t-1} \cdot v\left(b_{2 t}\right)$,

subject to the government budget constraint given by equation (1). It follows immediately that $u^{\prime}=v^{\prime}$ at the optimal levels of benefits. Thus if the two utility functions are identical, the optimal benefits of young retirees and older retirees are equal in each period: $b_{1 t}^{*}=b_{2 t}^{*}{ }^{6}$

Since real wages are rising at rate $g$ per period, the common level of benefit is also increasing at rate $g$ per period. The equality of benefits of the younger and older retirees at each point in time therefore means that the optimal level of each individual's own benefits increases at rate $g$ between the early retirement period and the late retirement period.

\section{The Optimal Annuity Structure for Rational Egoists: The Initial Retirees}

The present section drops the assumption that all individuals are completely myopic in favor of the alternative extreme assumption that everyone is a rational life-cycle saver. To show the importance of unintended bequests, the analysis assumes that the individuals are "egoists" who care only about their own utility and who give no weight to the bequests received by the next generation. Since the analysis in this section completely ignores the effect of social security benefits on bequests received, it represents the appropriate analysis for the "initial" generation of retirees. The results of this section can then be compared with those of section 3 in which the individual utility criterion reflects the effect of the age structure of social security benefits on the value of the unintended bequests that result from premature death, i.e., in which the individual entering the labor force "chooses" the social security 
benefit structure knowing that it will affect the bequests that he receives as as well as the expected value of the bequests that he will make.

Although the current criterion ignores the effect of the social security benefit structure on the bequests that are made, the individual's budget constraint does depend on the bequests that he received during his own preretirement years. More specifically, the analysis now assumes that each individual chooses a path of desired consumption levels based on his wage income, inherited bequests and social security benefits that maximizes expected utility. This consumption path implies the accumulation of assets during working years which, together with the social security benefits, finances consumption during retirement. If the individual dies at the end of the first period of retirement, those assets are bequeathed. In deciding his own path of consumption, the egoistic individual assigns no value to those unintended bequest. No private annuities are available.

To derive explicit results, I will now adopt the $\log -1$ inear utility specification ${ }^{7}$ used in the social security models of Feldstein (1985, 1987) and posit that individuals who will retire in period $t$ maximize

(4) $U_{t}=\ln c_{1, t-2}+\ln c_{2, t-1}+\ln c_{3, t}+p \ln c_{4, t+1}$ subject to the individual's lifetime budget constraint

$$
\begin{gathered}
\text { (5) }\left[(1-\theta) w_{t-2}+B_{t-2}-c_{1, t-2}\right](1+r)^{3}+\left[(1-\theta) w_{t-1}-c_{2, t-1}\right](1+r)^{2} \\
+\left(b_{1 t}-c_{3 t}\right)(1+r)+b_{2, t+1}-c_{4, t+1}=0
\end{gathered}
$$

where $B_{t-2}$ is the bequest received when the individual is a young worker in period t-2. Although an individual can borrow or lend to transfer 
resources between periods, an individual cannot leave a negative bequest; planned consumption in the final period must therefore be not less than the social security benefit $\left(c_{4, t+1} \geq b_{2, t+1}\right)$. If this condition is satisfied (an assumption that will be verified later), it follows directly that the individual's optimal consumption plan is:

$$
\begin{aligned}
c_{s, t+s-3}^{*} & \frac{p^{k}(1+r)^{s-1}}{3+p}\left\{(1-\theta) w_{t-2}[1+(1+g) /(1+r)]+B_{t-2}\right. \\
& \left.+b_{1 t} /(1+r)^{2}+b_{2, t+1} /(1+r)^{3}\right\}
\end{aligned}
$$

where $k=1$ for $s=4$ and $k=0$ for the previous periods.

Substituting these optimal consumption levels into the lifetime utility function of equation 4 and collecting similar terms shows that

(7) $U_{t}-A_{1}+(3+p) \ln \left\{(1-\theta) w_{t-2}[1+(1+g) /(1+r)]+B_{t-2}\right.$

$$
\left.+b_{1 t} /(1+r)^{2}+b_{2, t+1} /(1+r)^{3}\right\}
$$

where $A_{1}$ depends on $p$ and $r$ but not on the benefits, bequest or tax rate. The individual's preferred benefit structure maximizes $U_{t}$ subject to the government budget constraint that equates the total benefits paid at time to the available revenue:

(8) $b_{1 t} R_{t}+b_{2 t} p R_{t-1}=\theta w_{t} L_{t}$ and to the steady state path requirement that each type of benefit increases over time at the same rate as wages (and thus that $b_{2, t+1}=b_{2, t}$ 
$(1+g)$.) Dividing each term in equation 8 by the number of new retirees $R_{t}$ implies that the budget constraint can be written:

(9) $b_{1 t}+p b_{2 t}(1+n)^{-1}-\theta w_{t}\left[(1+n)+(1+n)^{2}\right]$

To focus on the optimal age structure of benefits, $\theta$ (and therefore total benefits) is taken as fixed. With $b_{2, t+1}-b_{2, t}(1+g)$, maximizing $U_{t}$ of equation 7 subject to the government budget constraint is equivalent to maximizing

(10) $b_{1 t}+[(1+g) /(1+r)] b_{2 t}$

subject to equation 9 . Since (9) and (10) are both 1 inear in $b_{1 t}$ and $b_{2 t}$ ' it follows directly that the optimum is a corner solution in which all of the benefits are paid either to new retirees or to older retirees but not to both.

More specifically, individual utility is an increasing function of $b_{1 t}$ if $(1+g) /(1+r)<p /(1+n)$ and a decreasing function of $b_{1 t}$ if $(1+g) /(1+r)>$ $p /(1+n)$. Since both benefits must be non-negative, $(1+g) /(1+r)<p /(1+n)$ implies that the preferred social security program would be a lump sum to new retirees with no benefits to older retirees. Conversely, if $(1+g) /(1+r)>p /(1+n)$, the preferred program would pay no benefit to new retirees and a lump sum to those who survive to the second period.

To understand this result, note that the key inequality can be restated as a comparison of the survival probability $p$ and the "efficiency of social security," $x=(1+n)(1+g) /(1+r)$. This term can be characterized as the efficiency of social security because it compares the implicit return on social security $[(1+n)(1+g)]$ to the return earned on private 
assets $(1+r) .^{8}$ Previous analysis (e.g., Feldstein (1985)) has emphasized that since social security is inefficient in the sense that $x<1$, a social security program is justified only to the extent that the provision of benefits to those myopic individuals who would otherwise save too little outweighs the losses to the rational life cyclers who are forced to sacrifice a return of $1+r$ in exchange for a return of $(1+n)(1+g)$.

In the present context in which the size of the overall social security program is fixed and in which all individuals are rational life cyclers, the comparison of $x$ and $p$ indicates whether the gain from social security's ability to provide a fair annuity outweighs the loss due to its lower rate of return. If $x<p$, the return on social security is so low that individuals are better off receiving a lump sum social security benefit when they retire with no second period benefit at all. Another way of stating this is to note that $x<p$ is equivalent to $(I+g)(I+n)<p(I+r)$, i.e., the return provided by the social security annuity $[(1+g)(1+n)]$ is less than the return from private saving reduced by the mortality probability $[\mathrm{p}(1+\mathrm{r})]$.

In the alternative case, the low return on the social security annuity is nevertheless great enough to exceed the expected return on private saving: $(1+g)(1+n)>p(1+r)$ or $x>p$. In this case, the preferred social security program pays the benefits only to those who survive to the second period of retirement.

A numerical example will indicate the nature of this comparison. Assume for simplicity that younger retirees are age 70 (i.e., the midpoint of the decade 65 to 75 ) and that older retirees are 85 years old. For American males, the probability that a 70 year old will survive to age 85 
is 0.49 . Using the average annual growth rates of population ( 1.4 percent) and real wages (2.3 percent) for the three decades from 1950 through 1980, the 15 year return on social security is $(1+g)(1+n)-1.73$. If the real rate of return available on savings is six percent per year, for the 15 year period $1+r-2.40$ and the efficiency of social security is $x-$ $1.73 / 2.40-0.72$ and therefore substantially greater than the survival probability of 0.49 . In this case, benefits should be postponed and given only to the older retirees. If the return on private savings is taken to be the pretax real return on nonresidential capital or approximately 11.5 percent (see Feldstein, Poterba and Dicks-Mireau, 1983), so that $1+\mathbf{r}=$ 5.12 and the efficiency of social security is only 0.34 , the basic inefficiency of social security dominates the effect of providing a fair annuity $(x<p)$ and therefore that benefits should be paid only to the younger retirees.

Two comments on the results of this section are in order. First, paying all of the benefits to the older retirees could cause the consumption path implied by equation 6 to violate the constraint that $c_{4, t+1} \geq b_{2, t+1}$, i.e., that the potential bequest at the end of the first retirement period must be non-negative. If this constraint is binding, it must be imposed explicitly and the optimal consumption path and optimal benefits recalculated. Doing so will imply an interior solution for the two benefit levels: $b_{1 t}>0$ and $b_{2, t+1}>0$. It can never imply that all of the benefits should be paid during the first retirement period.

Second, it should be emphasized that the extreme result that it might be optima1 to give no benefit in one of the two periods reflects the lack of any myopia in the population. Whenever some individuals are completely 
myopic, it is necessarily optimal to pay benefits in both periods. Although any realistic analysis of the optimal age structure of benefits would have to deal with myopia as well as imperfect annuity markets, the basic analytic significance of balancing the imperfect annuity market and the inefficiency of social security is clearer if myopia is ignored.

\section{Endogenous Bequests and the Optimal Steady State Age Structure of Benefits}

The results derived in section 2 show the age structure of benefits that maximizes the welfare of a representative worker of the initial retiree generation. It does not recognize that the bequests received by each generation of workers depends on the age structure of the social security benefits anticipated and received by a previous generation of retirees. Promising a high level of benefits to older retirees reduces their optimal saving for their very old age and therefore reduces the unintended bequests that are made by those who die at the end of their first retirement period. A social welfare function that properly recognizes that the welfare of each cohort is affected in this way by the benefit structure faced by previous cohorts will imply that the optimal level of benefit paid to older retirees is generally less than (although possibly equal to) that derived in the previous section.

The present section extends the analysis of section 2 by explicitly recognizing the effect of the benefit structure on the level of unintended bequests. It shows that in a very simple model with rational life cycle savers (no myopia), complete egoism (no altruistic bequests) and logarithmic utility functions, the age structure of benefits that maximizes steady state utility always gives all of the benefits to the younger 
retirees unless social security is fully efficient $(x \geq 1) .9$ Thus in this case the unintended bequests that result form the payment of early benefits always outweigh the gain from providing an improved annuity as long as private saving has a higher return than social security $(x<1)$. The key reason for this difference is that the total return to saving for the older age is now recognized as being received by someone -- either the surviving retiree or the deceased retiree's heir .. and therefore as long as the return on that saving exceeds the return on social security $(x<1)$, it increases steady state welfare to have the funds invested in real assets.

To analyze this problem, I assume that the unintended bequests made at time $t$ are divided equally among all of the young workers alive at time t. ${ }^{10} \mathrm{~A}$ worker who would have been an older retiree at time $t$ but who dies prematurely leaves a bequest equal to $c_{4, t}-b_{2 t}$. the excess of planned consumption over the social security benefit that would have been received had the individual lived. Since the proportion 1-p of those in this age cohort do die prematurely and there are $(1+n)^{3}$ as many young workers as there are members of the original cohort of older retirees, the bequest received by each young worker is:

(11) $B_{t}=(1+n)^{-3}(1-p)\left(c_{4, t}^{t}-b_{2, t}\right)$.

The utility of the representative individual who retires at time $t$ is given by

$$
u_{t}=\ln c_{1, t-2}+\ln c_{2, t-1}+\ln c_{3, t}+p \ln c_{4, t+1}
$$

Equation 6, which states the individual consumption choices as functions of wage income, benefits and received bequests, implies: 
(13) $c_{4, t+1}^{*}=(1+r)^{3} \frac{p}{3+p}\left[(1-\theta) w_{t-2}[1+(1+g) /(1+r)]+B_{t-2}+b_{1 t}(1+r)^{-2}\right.$

$$
\left.+b_{2, t+1}(1+r)^{-3}\right]
$$

Noting that equation 11 holds at every point in time and using the fact that all per capita amounts grow at rate $g$ along the equilibrium path implies

$$
\text { (14) } B_{t-2}=(1+n)^{-3}(1-p)\left(c_{4, t+1}^{*}-b_{2, t+1}\right)(1+g)^{-3} \text {. }
$$

Equations 13 and 14 can be combined to eliminate $B_{t-2}$ and therefore to restate consumption as a function of wage income and benefit rules. Note that the individual utility maximization decision that produces 13 is egoistic and gives no weight to the bequests that might accrue to future generations. The relation between benefits and consumption that works through bequests is an equilibrium property of the process and not of individual preferences for making bequests.

Equations 13 and 14 together imply

$$
\begin{aligned}
c_{4, t+1}^{*} & =(1+r)^{3} \frac{p}{3+p}\left[\frac{(3+p) x^{3}}{(3+p) x^{3}-p(1-p)}\right]\left\{(1-\theta) w_{t-2}[1+(1+g) /(1+r)]\right. \\
& \left.+b_{1 t^{\prime}} /(1+r)^{2}+\frac{b_{2, t+1}}{(1+r)^{3}}\left[\frac{x^{3}-(1-p)}{x^{3}}\right]\right\} .
\end{aligned}
$$

More generally, the other consumption terms can be derived using the relative values indicated by equation 6 and by the fact that along the equilibrium path $c_{s, t+k}^{*}=(1+g)^{k} c_{s, t}^{*}$. Thus 
(16) $c_{s, t}^{*}=\frac{(1+r)^{s-1}(1+g)^{3-s} p^{k} x^{3}}{(3+p) x^{3}-p(1-p)}\left\{(1-\theta) w_{t-2}[1+(1+g) / 1+r)\right]+b_{1 t}(1+r)^{-2}$

$$
\left.+b_{2, t+1}(1+r)^{-3}\left[1-(1-p) x^{-3}\right]\right\}
$$

where $k=1$ for $s-4$ and $k=0$ otherwise.

It is clear from equation 16 that all of the $c_{s, t}^{*}$ at time $t$ are proportional to the expression in brackets (which is independent of $s$ ) and that they differ only by the numerator of the term that precedes the bracketed expression (which is independent of the age structure of benefits). Choosing $b_{1 t}$ and $b_{2 t}$ to maximize any $c_{\text {st }}$ subject to the budget constraint

$$
b_{1 t}+p b_{2 t}(1+n)^{-1}=\text { constant }
$$

therefore maximizes all the $c_{s t}$ at time $t$. This follows because $b_{1 t}$ and $b_{2 t}$ influences the $c_{s t}$ 's only through the individuals' lifetime budget constraints. 11

The representative utility function of equation 12 is maximized by maximizing the $c_{s t}$. The optimal steady state age structure of benefits is therefore obtained by maximizing equation 16 subject to the budget constraint of equation 17 and the equilibrium path condition that $b_{2, t+1}=$ $(1+g) b_{2 t}$

Combining 16 and 17 to eliminate $b_{2 t}$ yields

$$
c_{s, t}^{*}=A_{s, t}+\left\{\frac{p-x\left[1-(1-p) x^{-3}\right]}{p(3+p) x^{3}-p^{2}(1-p)}\right\} b_{1 t}
$$


where $A_{s, t}$ does not depend on $b_{1 t}$. It follows immediately that steady state social welfare is maximized by setting $b_{1 t}=0$ if the expression in brackets is negative and by setting $b_{2 t}=0$ (and therefore maximizing the feasible value of $b_{1 t}$ ) if the expression in brackets is positive.

Consider first the case in which social security is fully efficient, i.e., in which $x-1$. The numerator of the expression is 18 to their identically zero and steady state welfare is not affected by the age structure of the social benefits.

In the more relevant case in which social security is inefficient $(x<1)$, equation 18 implies that it is optimal to pay all of the benefits to new retirees: $b_{2 t}=0$ and $b_{1 t}>0$. To demonstrate this, assume first that the denominator of the bracketed expression is positive. Note that at $\mathrm{p}=0$ the numerator equals $-\mathrm{x}\left[1-\mathrm{x}^{-3}\right]>0$ and at $\mathrm{p}=1$ the numerator equals $1-\mathrm{x}$ $>0$. Since the value of the numerator decreases monotonically with $p$ (at rate $1-x^{-2}$, the numerator is positive at all feasible values of $0 \leq p \leq 1$. It follows therefore that steady state social welfare is maximized by setting $b_{2 t}=0$ and having the highest value of $b_{1 t}$ compatible with the government budget constraint.

For any given value of $p, a$ low enough value of $x$ makes the denominator negative. Although a literal interpretation of equation 18 would suggest that in this case $b_{1 t}$ should be zero, this is a false conclusion. It is clear from the economics of the problem that reducing $x$ (i.e., making social security less efficient) increases the advantage of giving benefits earlier. This can be seen in equation 18 since, as long as the denominator of the bracketed expressive is positive, the value of the bracketed expression as a whole varies inversely with $x$. When $x$ gets below 
a certain critical value, the sign of the denominator changes as the effect of $b_{1 t}$ on consumption and steady state welfare appear (falsely) to be reversed. In fact, when $x$ drops below that critical value the system becomes unstable in the sense that the shift of benefits from the older aged to the younger aged causes the ratio of inherited wealth to labor income to increase over time without limit. In such a situation there is no steady state level of consumption and equation 18 is invalid. It

remains true however that $b_{2 t}-0$ and $b_{1 t}>0$ maximizes the log-run path of consumption and social welfare.

It should be emphasized that the results of this section refer to the benefit structure that maximizes the steady state level of social welfare. The analysis of section 2 showed that the welfare of the initial generation will be increased by paying benefits to older retirees whenever $p<x$. Thus the optimal permanent structure of benefits is unambiguous only when $\mathrm{p}<\mathrm{x}$. In the reverse case (when social security is efficient enough to outweigh the lack of private annuities) the optimal permanent structure of benefits requires an explicit intertemporal social welfare function balancing the utilities of different generations. A high enough discount rate makes such an intertemporal welfare function equivalent to maximizing the welfare of the initial generation. As the discount rate declines, the optimal structure of benefits shifts in the direction of increased benefits for younger retirees. See Feldstein (1985) for an explicit example of the intertemporal welfare function in this context.

More generally, the very strong result that paying benefits to younger retirees maximizes steady state welfare reflects the very special assumption that everyone is a rational life-cycle saver. Introducing 
myopia in the population would make it optimal to provide benefits for the older aged as well. What the current analysis brings out, however, is that taking into account the effect on bequests of the age structure of benefits reduces the ratio of the optimal benefit of older retirees to the optimal benefit of younger retirees.

\section{Concluding Comment}

This paper has begun an exploration of the important issue of how social security benefits should vary with the age of the recipient in an economy with imperfect annuity markets. Three formal results are derived.

(1) When everyone is myopic and has the same utility function, all retirees should receive the same benefit at each point in time. In an economy in which real wages rise with time, benefits rise as the individual ages.

(2) Egoistic rational life-cyclers in the initial generation of retirees (whose inheritances are unaffected by the structure of social security) prefer to postpone benefits until their later retirement years if and only if the "efficiency" of social security (the implicit return on social security relative to the return on private investments) is high enough relative to the probability of surviving from initial retirement to older age. When the "efficiency" of social security is low, they prefer benefits to be paid immediately upon retirement.

(3) Looking beyond the initial generation of retirees and taking into account the effect of social security benefits on the bequests to future generations implies that steady state utility is maximized by paying benefits only to young retirees since shifting benefits to an earlier 
period increases saving and therefore unintended bequests and the aggregate capital stock.

Because the models analyzed here are very simple, the results are only of suggestive and heuristic value. The problem deserves further analysis with more realistic models. Such analysis would recognize the existence of imperfect annuity markets (rather than assuming that no private annuities exist) and of private group pension annuities that are fixed in nominal terms. The role of individual myopia would be specifically incorporated. The implications of imperfect annuity markets and unintended bequests for the optimal size of the social security program and for the desirability of means testing should also be explored. 


\section{Footnotes}

1. On the absence of actuarial fair annuities, see Friedman and Warshawsky $(1985 \mathrm{a}, 1985 \mathrm{~b})$. In practice individuals may also not buy annuities because of their lack of understanding of annuities or an irrational fear of "betting" on a long life.

2. See Feldstein (1985) for an analysis that shows that it may be optimal to have no social security in an economy in which the implicit return on social security is low even though individuals save too little privately for their own old age.

3. Feldstein (1985) uses two different models of partial myopia to discuss the optimal level of social security benefits. In one model, all individuals are "partially myopic" and give less than the full weight to future utility. In the alternative model, a fraction of the population is completely myopic while everyone else is a fully rational life-cycle saver. 4. Even the distinction between intended and unintended bequests is ambiguous when younger individuals do not know what their income will be later in life. See Feldstein (1988).

5. Feldstein (1987) discussed the conditions under which a means tested social security program is preferable to a universal program.

6. Although it is of course possible to argue that differences in the utility function imply a different benefit structure, it is not clear in which direction this points. Younger retirees may have a higher marginal utility of consumption at each level of spending because they are healthier and therefore able to engage in a broader range of activities. Alternatively, they older retirees may have a higher marginal utility of consumption at each level of spending because they have higher fixed costs 
for medical care and other personal services. While recognizing both possibilities, the present analysis proceeds on the assumptions that both utility functions are the same. Note that even if the individual discounts second period utility, the social welfare function reflects utility at a point in time and therefore should not incorporate such a discount.

7. The basic results derived here are valid for any homothetic utility function. Equations 6 and 7 show that maximizing lifetime utility is equivalent to maximizing the present value of lifetime resources since utility depends additively on consumption and consumption is each period is proportional to the present value of lifetime resources, a property of any homothetic utility function.

8. Note that an "inefficient social security system $(x<1)$ corresponds to an economy that is dynamically efficient in the traditional sense. 9. The analysis here is in terms of the utility of a representative individual in the steady state. The analysis is easily shown to be formally equivalent to maximizing the sum of all of the utilities of everyone alive at a point in time if the additively separable individual utility functions are given the necessary cardinal interpretation. A complete intertemporal utility function requires aggregating the utilities of the "initial generation" whose inheritances are unaffected by the choice of the age structure of social security benefits and the subsequent generations whose inheritances depend on the age structure of social security benefits; this issue is discussed further at the end of the current section. 
10. A model that recognized that only some workers in each generation receive bequests would lead to stochastic distributions of bequests and of consumption among the individuals of each age cohort. Because of diminishing marginal utility, the unequal distribution of bequests would reduce the welfare value of bequest (relative to the current model). Recognizing the effect of the benefit structure on bequests would therefore imply a smaller increase in the optimal level of benefits of younger retirees than when all are assumed to receive equal bequests. 11. This implies that the results of this section also hold for any homothetic utility function. 


\section{$\underline{\text { References }}$}

Feldstein, Martin (1985), "The Optimal Level of Social Security Benefits," Quarterly Journal of Economics.

, (1987), "Should Social Securlty Benefits be Means Tested?", Journal of Political Economy, June.

Friedman, Benjamin and Mark Warshawsky (1985), "Annuity Prices and Saving Behavior in the United States," NBER Working Paper No. 1683.

Cambridge, MA: National Bureau of Economic Research.

Friedman, Benjamin and Mark Warshawsky (1985), "The Cost of Annuities: Implications for Saving Behavior and Bequests," NBER Working Paper No. 1682. Cambridge, MA: National Bureau of Economic Research.

Samuelson, Paul (1985), "An Extract Consumption Loan Model of Interest With or Without the Social Contrivance of Money," Journal of Political Economy, December.

U.S. Department of Commerce, Bureau of Census (1986), Statistical Abstract of the United States, Washington, D.C.: U.S. Government Printing Office. 